\title{
Trpv5/6 is vital for epithelial calcium uptake and bone formation
}

\author{
Jo Vanoevelen, ${ }^{*}, 1$ Annelies Janssens, ${ }^{\dagger}$ Leonie F. A. Huitema, ${ }^{*}$ Christina L. Hammond, ${ }^{*}$ \\ Juriaan R. Metz, ${ }^{\ddagger}$ Gert Flik, ${ }^{\ddagger}$ Thomas Voets, ${ }^{\dagger}$ and Stefan Schulte-Merker* ${ }^{*}, \mathrm{~s}$ \\ *Hubrecht Institute, Royal Netherlands Academy of Arts and Sciences and University Medical \\ Centre, Utrecht, The Netherlands; ${ }^{\dagger}$ Laboratory for Ion Channel Research, Department of Molecular \\ Cell Biology, Catholic University Leuven, Leuven, Belgium; ${ }^{\ddagger}$ Institute for Water and Wetland \\ Research, Department of Animal Physiology, Radboud University, Nijmegen, The Netherlands; and \\ ${ }^{\S}$ Experimental Zoology Group, Wageningen University, Wageningen, The Netherlands
}

ABSTRACT Calcium is an essential ion serving a multitude of physiological roles. Aside from its role as a second messenger, it is an essential component of the vertebrate bone matrix. Efficient uptake and storage of calcium are therefore indispensable for all vertebrates. Transient receptor potential family, vanilloid type (TRPV)5 and TRPV6 channels are known players in transcellular calcium uptake, but the exact contribution of this pathway is unclear. We used forward genetic screening in zebrafish (Danio rerio) to identify genes essential in bone formation and identified a lethal zebrafish mutant (matt-und-schlapp) with severe defects in bone formation, including lack of ossification of the vertebral column and craniofacial structures. Mutant embryos show a $68 \%$ reduction in calcium content, and systemic calcium homeostasis is disturbed when compared with siblings. The phenotype can be partially rescued by increasing ambient calcium levels to $25 \mathrm{mM}$. We identified the mutation as a loss-of-function mutation in the single orthologue of TRPV5 and 6, trpv5/6. Expression in HEK293 cells showed that Trpv5/6 is a calcium-selective channel capable of inward calcium transport at physiological concentrations whereas the mutant channel is not. Taken together, this study provides both genetic and functional evidence that transcellular epithelial calcium uptake is vital to sustain life and enable bone formation.-Vanoevelen, J., Janssens, A., Huitema, L. F. A., Hammond, C. L., Metz, J. R., Flik, G., Voets, T., Schulte-Merker, S. Trpv5/6 is vital for epithelial calcium uptake and bone formation. FASEB J. 25, 000-000 (2011). www.fasebj.org

Key Words: zebrafish • osteogenesis

CAlcium $\left(\mathrm{CA}^{2+}\right)$ IS AN ESSENTIAL ion that serves many physiological roles, both extra- and intracellularly. Carefully controlled intracellular $\mathrm{Ca}^{2+}$ concentrations are therefore indispensable to fulfill a range of biological functions, including muscle contraction, synaptic transmission, cell death, and many more $(1,2)$. In vertebrates, bone serves as an important $\mathrm{Ca}^{2+}$ store for systemic homeostasis, and plasma $\mathrm{Ca}^{2+}$ is in equilib- rium with $\mathrm{Ca}^{2+}$-hydroxyapatites in the bone matrix (3). Since such a wide variety of processes depend on the availability of $\mathrm{Ca}^{2+}$, it is crucial that sufficient amounts of $\mathrm{Ca}^{2+}$ are taken up and the $\mathrm{Ca}^{2+}$ levels in body fluids are kept within a narrow concentration range $(2-3 \mathrm{mM}$; ref. 4$)$.

Terrestrial vertebrates acquire sufficient $\mathrm{Ca}^{2+}$ from ingested food, and the intestine therefore is the main site of uptake. There exist $2 \mathrm{Ca}^{2+}$ uptake pathways: an energy-dependent transcellular pathway and a passive paracellular pathway (5). In the transcellular pathway, $\mathrm{Ca}^{2+}$ enters the enterocytes through the apical membrane via a $\mathrm{Ca}^{2+}$-permeable channel of the transient receptor potential family, vanilloid type (TRPV)6 (6). In the cytosol of the enterocyte, $\mathrm{Ca}^{2+}$ ions are readily complexed to $\mathrm{Ca}^{2+}$-buffering proteins like calbindin$\mathrm{D}_{9 \mathrm{~K}}(7)$. At the basal side of the epithelium, $\mathrm{Ca}^{2+}$ is actively extruded via plasma membrane $\mathrm{Ca}^{2+}$-ATPase 1 (PMCA1; ref. 8) and $\mathrm{Na}^{+} / \mathrm{Ca}^{2+}$ exchanger 1 (NCX1; ref. 9) and thus enters the blood and can be transported throughout the body. In addition, there exists a renal reabsorption pathway in which $\mathrm{Ca}^{2+}$ is taken up from the forming urine. Initial uptake in the kidney tubules occurs via TRPV5 (10), and basolateral transport is also achieved through NCX1 and PMCA1 (11). The paracellular route involves passive diffusion and mainly depends on $\mathrm{Ca}^{2+}$ concentration gradients and the tightness of the epithelium $(12,13)$. The molecular principles for transepithelial $\mathrm{Ca}^{2+}$ transport are highly conserved between fish and mammals (14), although their habitat is different; ambient water provides a sufficient source of $\mathrm{Ca}^{2+}$ (seawater: $10 \mathrm{mM}$; freshwater: $0.025-3.0 \mathrm{mM})$. In fish, $\mathrm{Ca}^{2+}$ is taken up mainly ( $\sim 97 \%$ ) by the gills, and chloride cells have long been recognized as the main cell type involved in this process

\footnotetext{
${ }^{1}$ Correspondence: Laboratory for Cellular Transport Systems, Department of Molecular Cell Biology, Catholic University Leuven, Herestraat 49, 3000 Leuven, Belgium. E-mail: jo.vanoevelen@med.kuleuven.be

doi: 10.1096/fj.11-183145

This article includes supplemental data. Please visit $h t t p: / /$ www.fasebj.org to obtain this information.
} 
$(4,15)$. These cells contain all molecular components (Trpv5/6, Pmcas, and Nxc-homologues) that are thought to play a role in transepithelial $\mathrm{Ca}^{2+}$ uptake (16), although their contribution has never been studied at the molecular level.

The transient receptor potential (TRP) family is a large protein family consisting of several subfamilies, of which the TRPV is an example. The TRPV family can be divided into 4 groups: TRPV1/2, TRPV3, TRPV4, and TRPV5/6 (reviewed in ref. 17). TRPV1-TRPV4 are nonselective cation channels that can be activated by a number of different stimuli, such as second-messenger binding, heat and cold, and chemical and/or mechanical stress $(18,19)$. These channels are modestly permeable for $\mathrm{Ca}^{2+}$, whereas the other 2 members of the family, TRPV5 and TRPV6, are highly selective for $\mathrm{Ca}^{2+}$ and tightly regulated by intracellular $\mathrm{Ca}^{2+}$ concentration $(20-22)$.

An important question remaining in the field of epithelial $\mathrm{Ca}^{2+}$ transport concerns the exact contribution of the transcellular $v$ s. the paracellular pathway (23, 24). Mouse single-knockout models for components of the transcellular pathway, Trpv5 and Trpv6, failed to answer this question due to functional redundancy and compensatory mechanisms by other genes and pathways regulating $\mathrm{Ca}^{2+}$ homeostasis, including parathyroid hormone- and vitamin D-dependent mechanisms $(25,26)$.

The vertebrate body contains a large pool of immobilized $\mathrm{Ca}^{2+}$ in the skeleton. Besides its role in $\mathrm{Ca}^{2+}$ storage, bones are important in supporting the vertebrate body, enabling movement by providing a matrix for the attachment of muscles and tendons and protection of important organs like the brain and heart (27). Skeletal homeostasis is established by balancing bone formation through the activity of osteoblasts and through bone resorption by osteoclasts, processes that exhibit a large extent of evolutionary conservation between fish and mammals (28). We used forward genetic screening in zebrafish to identify genes critically involved in bone formation and identified the single orthologue of mammalian TRPV5/6 as a main regulator of bone formation and transepithelial $\mathrm{Ca}^{2+}$ uptake, establishing an in vivo model for this essential physiological process.

\section{MATERIALS AND METHODS}

\section{Screening procedure}

Forward genetic screening was performed as described by Spoorendonk et al. (29).

\section{Molecular biology}

The cDNA encoding trpv5/6 was amplified from reversetranscribed RNA and ligated into a pGEM-T easy (Promega, Madison, WI, USA) cloning vector. For expression in HEK293 cells, the ends of the cDNA were modified with appropriate restriction sites using PCR and ligated into the pCINeo/IRESGFP vector.

\section{Meiotic mapping}

The matt-und-schlapp mutation was mapped to linkage group 16 using standard simple sequence length polymorphism (SSLP) mapping. Fine mapping was performed using custom repeat markers and single-nucleotide polymorphisms (SNPs). Primer sequences are as follows: Rep12For 5'-TGGAGATTACTGTAGGTCAGAACA-3', Rep12Rev 5'-CTGTGAAAATTGCCTTGCTC3'; SNPAFor 5'-CCATCACTGGTGTTTTGGACT-3', SNPARev 5'-TGAAGGAAAGCTGGTCATTTG-3'; and SNPBFor 5'-TTCTAGTGTGGACGGTGCAA-3', SNPBRev 5'-CACCACGTTCTTGTAATGTCA-3'.

\section{Skeletal staining}

The protocol for bone and cartilage staining was adapted from Walker and Kimmel (30). Embryos were fixed in 3.5\% formaldehyde and stored in $70 \%$ methanol at $4^{\circ} \mathrm{C}$ until further use. Embryos were partially dehydrated in $50 \%$ ethanol and stained with $0.2 \mathrm{mg} / \mathrm{ml}$ Alcian blue $8 \mathrm{GX}$ (Sigma, St. Louis, MO, USA) in $70 \%$ ethanol containing $80 \mathrm{mM} \mathrm{MgCl}_{2}$. Next, embryos were bleached in $1 \% \mathrm{H}_{2} \mathrm{O}_{2} / 1 \% \mathrm{KOH}$ for 30 min, washed in a saturated sodium tetraborate solution, and digested for $1 \mathrm{~h}$ in $1 \mathrm{mg} / \mathrm{ml}$ trypsin (Sigma) in $60 \%$ sodiumtetraborate. Bone was stained with $0.04 \mathrm{mg} / \mathrm{ml}$ Alizarin red $\mathrm{S}$ (Sigma) in $1 \% \mathrm{KOH}$. Finally, specimens were dehydrated to $70 \%$ glycerol and stored at $4^{\circ} \mathrm{C}$.

\section{In situ hybridization}

In situ hybridization was performed essentially as described previously $(31,32)$. Briefly, embryos were fixed in $4 \%$ paraformaldehyde in PBS, transferred to methanol, and rehydrated. Embryos were permeablilzed by proteinase-K treatment in PBS $+0.1 \%$ Tween 20 (PBST). Embryos were prehybridized for $2 \mathrm{~h}$ at $68^{\circ} \mathrm{C}$ before overnight hybridization at $68^{\circ} \mathrm{C}$ in hybridization solution $(50 \%$ formamide $5 \times \mathrm{SSC}$, $500 \mathrm{mg} / \mathrm{ml}$ yeast tRNA, $50 \mathrm{mg} / \mathrm{ml}$ heparin, $0.2 \%$ Tween 20 , and $9.2 \mathrm{mM}$ citric acid) containing digoxygenin-labeled antisense probes. Embryos were then washed in $2 \times$ SSCT (300 $\mathrm{mM} \mathrm{NaCl}, 15 \mathrm{mM}$ sodium citrate, and $0.1 \%$ Tween 20$)$ and taken to $0.2 \mathrm{SSCT}$ at $68^{\circ} \mathrm{C}$. After graded changes to PBS, embryos were blocked for $2 \mathrm{~h}$ with Roche blocking reagent (Roche, Indianapolis, IN, USA) in PBS at $4^{\circ} \mathrm{C}$ and subsequently incubated overnight with blocking reagent containing antidioxygenin antibodies labeled with alkaline phosphatase (Roche), diluted in blocking buffer. After being washed 6 times in PBST, embryos were transferred to alkaline phosphate buffer (100 mM Tris, $50 \mathrm{mM} \mathrm{MgCl}$, $100 \mathrm{mM} \mathrm{NaCl}$, and $0.1 \%$ Tween 20), and staining was developed using nitroblue tetrazolium/5-bromo4-chloro-3-indolyl phosphate. Primer sequences used to generate in situ probes were as follows: trpv $5 / 6-5^{\prime}$ probeFor $5^{\prime}$-GGGATGGAATGAAATGTTGG-3', trpv5/6-5' probeRev 5'-GTGTTCATCGACCCTGGAGT-3'; Stc-1.2For 5'-GCAAACATCTCCTGCTTTGG-3', Stc-1.2Rev 5'-TCGATATCCTGCACACTTGC-3'; Ron2For 5'-GTCTTCCGCATTGGACACTT-3', Ron2Rev 5'-GCCGAGTCTTGTCTGAAAGG-3'; colla2-5'ProbeFor 5'-AAGGACTGCAAGGACATGCT-3', colla2-5'ProbeRev 5'-TGCTCTCCAGTTGACCCTCT-3'; coll0a1-5'ProbeFor 5'-TGCCCATGGTGAGAGATATG-3', col10a15'ProbeRev 5'-GCATACCAGGAGCACCATTC-3'; and sparcProbeFor 5'-TGAGGGTTTGGATCTTCTTCC-3', spardProbeRev 5'TGTCGACATCCTGCTCTTTG-3'. In situ hybridizations were performed at least 2 times, and embryos were genotyped afterward. 


\section{Genotyping}

Genomic DNA of single embryos was extracted and subjected to KASPar SNP genotyping (KBiosciences, Hoddesdon, UK) using protocols described by the manufacturer. Primer sequences are as follows: ForwardSib 5'-GAAGGTGACCAAGTTCATGCTGTGATTTGTTTGTCTCAGGCCAGAA-3' , ForwardMut 5'-GAAGGTCGGAGTCAACGGATTGTGATTTGTTTGTCTCAGGCCAGAT-3', and CommonReverse 5'-GATGAGCTGTCGGACTGGAGTCAA-3' .

\section{$\mathrm{Ca}^{2+}$ and phosphorous measurements}

Mutant and sibling embryos were phenotyped and overanesthetized using MS-222, washed twice with deionized water, and dried overnight under vacuum. Ions were released with $60 \%$ nitric acid. Next, samples were diluted using deionized water and measured using atomic absorption spectrophotometry (Solaar; Thermo Elemental, Winsford, UK; ref. 33). Statistical significance was determined using Student's $t$ test.

\section{Microscopy}

In situ hybridizations were analyzed on a Zeiss Axioplan microscope (Carl Zeiss, Göttingen, Germany) equipped with a Leica 480C camera (Leica, Wetzlar, Germany). For analyses in transgenic backgrounds, embryos were stained in vivo for bone with $0.05 \%$ Alizarin red, washed with E3 medium, anesthetized with MS-222, and embedded in $0.5 \%$ agarose. Images were captured on a Leica TCS-SPE confocal microscope. Intracellular $\mathrm{Ca}^{2+}$-imaging was performed using a Cell $^{\mathrm{M}}$ system (Olympus, Hamburg, Germany).

\section{Transgenic lines}

The osx:nuGFP line was generated as follows: the 4.1-kb upstream regulatory region of the medaka osterix gene was amplified (34) and cloned in front of a nuclear localization signal followed by GFP (nuGFP). Transgenic zebrafish were generated using the Tol2 transposon system (35). An osc:GFP reporter line was generated by amplification of a $3.5-\mathrm{kb}$ upstream regulatory region of the medaka osteocalcin gene and cloned in front of GFP (36).

\section{Evaluation of heart rates}

Embryos of 54 hours postfertilization (hpf) were anesthetized using MS-222 and transferred to 24-well plates and left to acclimatize for $30 \mathrm{~min}$. Heart rates were counted over intervals of $20 \mathrm{~s}$, and each embryo was evaluated 3 times before genotyping.

\section{Cell culture and transfections}

HEK-293 cells were grown in DMEM medium containing $10 \%$ (v/v) fetal calf serum, $2 \mathrm{mM}$ L-glutamine, $2 \mathrm{U} / \mathrm{ml}$ penicillin, and $2 \mathrm{mg} / \mathrm{ml}$ streptomycin at $37^{\circ} \mathrm{C}$ in an incubator with $10 \%$ $\mathrm{CO}_{2}$. They were transfected with the pCINeo/IRES-GFP/ trpv5/6 vector using TransIT-293 transfection reagent (Mirus, Madison, WI, USA), and electrophysiological recordings were performed $24 \mathrm{~h}$ later.

\section{Intracellular $\mathrm{Ca}^{2+}$-imaging}

Transfected cells were incubated with $2 \mu \mathrm{M}$ fura- 2 acetoxymethyl ester for $30 \mathrm{~min}$ at $37^{\circ} \mathrm{C}$. Intracellular $\mathrm{Ca}^{2+}$ concen- tration was monitored via the ratio of fluorescence measured on alternating illumination at 354 and $380 \mathrm{~nm}$ using an MT-10 illumination system and Cell ${ }^{\mathrm{M}}$ software (Olympus).

\section{Electrophysiology}

Transfected cells were identified by their green fluorescence. Patch-clamp experiments were performed in the tight-seal whole-cell configuration using an EPC-9 patch-clamp amplifier and Pulse software (HEKA Electronics, Lambrecht, Germany). Patch pipettes had DC resistances of 2-4 M $\Omega$ when filled with intracellular solution $\left(150 \mathrm{mM} \mathrm{NaCl}, 5 \mathrm{mM} \mathrm{MgCl}{ }_{2}\right.$, $5 \mathrm{mM}$ EGTA, and $10 \mathrm{mM}$ HEPES, $\mathrm{pH}$ 7.4). Series resistances were between 3 and $10 \mathrm{M} \Omega$ and were compensated $60-80 \%$. Currents were sampled at $10 \mathrm{kHz}$ and filtered at $2.9 \mathrm{kHz}$ using an 8-pole Bessel filter. The stimulation protocol consisted of a linear voltage ramp from -50 to $+100 \mathrm{mV}$ (in $400 \mathrm{~ms}$ ), which was applied every $5 \mathrm{~s}$. The divalent cation-free extracellular solutions contained $150 \mathrm{mM} \mathrm{XCl}$ [where $\mathrm{X}=\mathrm{Na}^{+}$, $\mathrm{K}^{+}$, or $N$-methyl-D-glucamine (NMDG)] and $10 \mathrm{mM}$ HEPES, titrated to $\mathrm{pH} 7.4$ with $\mathrm{XOH}$. Isotonic divalent cation solutions contained $100 \mathrm{mM} \mathrm{XCl}_{2}$ (where $\mathrm{X}=\mathrm{Ca}, \mathrm{Ba}$, or $\mathrm{Mg}$ ) and $10 \mathrm{mM}$ HEPES, titrated to $\mathrm{pH} 7.4$ with $\mathrm{X}(\mathrm{OH})_{2}$. For the anomalous mole fraction behavior, $\mathrm{NaCl}$ and $\mathrm{CaCl}_{2}$ solutions were mixed. All experiments were performed at room temperature $\left(20-22^{\circ} \mathrm{C}\right)$.

\section{$\mathrm{Ca}^{2+}$ enrichment and depletion}

Embryos were collected and transferred to modified E3 medium ( $5 \mathrm{mM} \mathrm{NaCl}, 0.17 \mathrm{mM} \mathrm{KCl}$, and $0.33 \mathrm{mM} \mathrm{MgSO}$; ref. 37) supplemented with the indicated amounts of total $\mathrm{Ca}^{2+}$ and incubated at $28,5^{\circ} \mathrm{C}$. Embryos were fixed at 7 days postfertilization ( $\mathrm{dpf}$ ) and processed for cartilage and bone staining.

\section{RESULTS}

\section{Matt-und-schlapp phenotype}

Matt-und-schlapp (German for "slack as a rag") embryos completely lack ossification of the axial skeleton (Fig. 1A). They fail to inflate their swim bladder and die at 7-9 dpf. Analysis of the phenotype at $7 \mathrm{dpf}$ revealed some phenotypic variability in terms of ossification (Fig. 1A). Mutants were scored as mild when they lacked ossification of the axial skeleton but possessed some normally ossified craniofacial elements such as cleithrum, opercle, parasphenoid, and the teeth on the fifth branchial arch. Mineralization of the teeth was reduced in the mild phenotype. Mutants were categorized as severe when all ossification was absent, except for the otoliths. Bright field images (Fig. 1A, insets) of the mutant embryos illustrate that the tip of the notochord is formed correctly, but ossification is absent. Otoliths (which are mineralized, nonbone structures) are present but remain smaller in size. All cartilage elements are present and indistinguishable between siblings and mutants.

\section{Matt-und-schlapp encodes trpv5/6}

Genome scan analysis linked the mutation to linkage group (LG) 16 (Fig. 1B). With the use of standard 


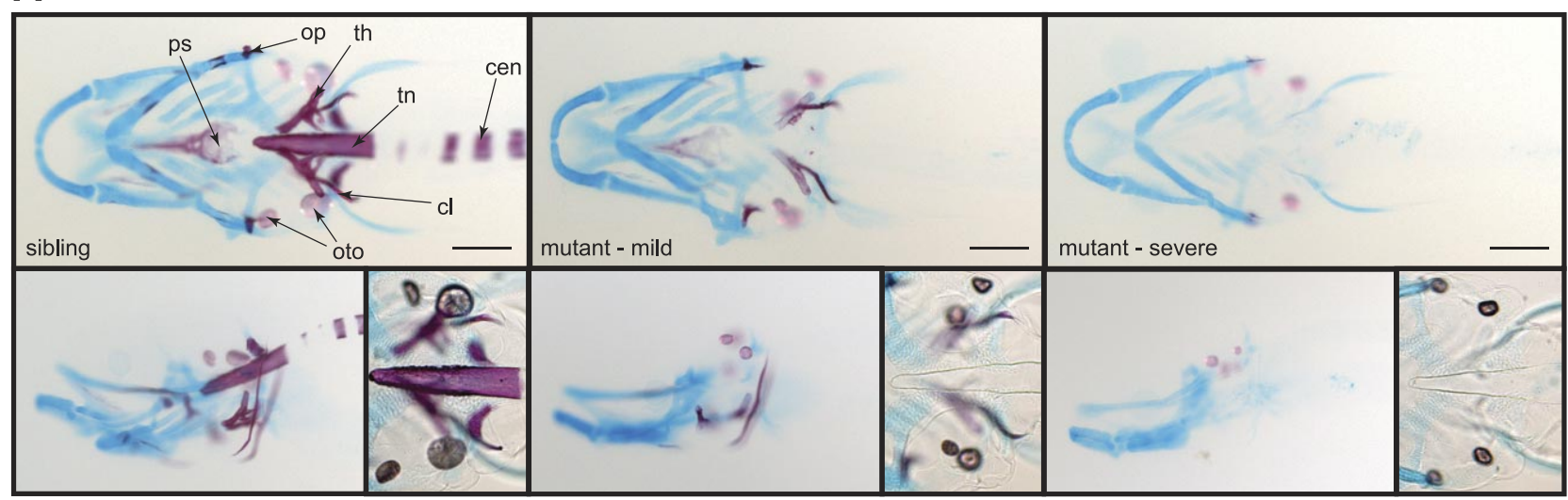

B

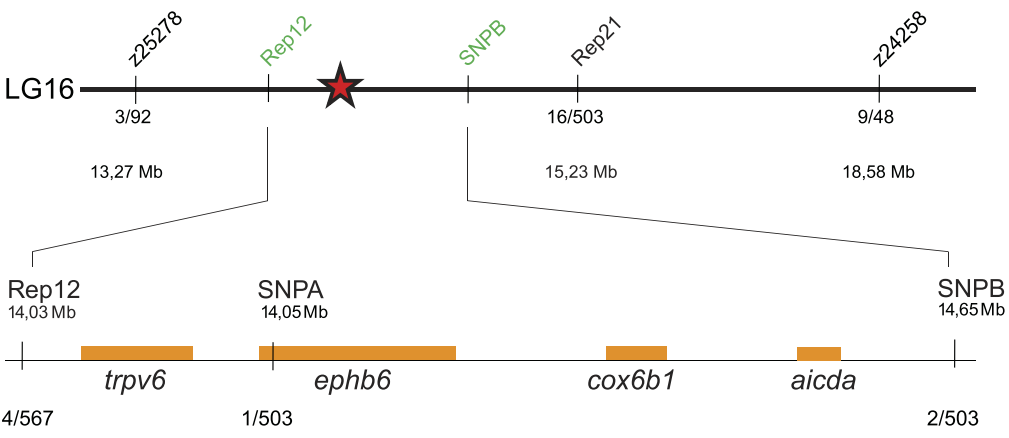

C

Het
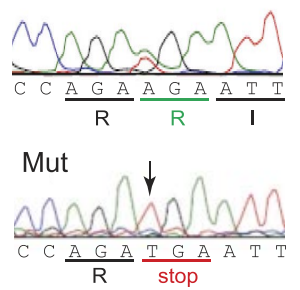

D

E

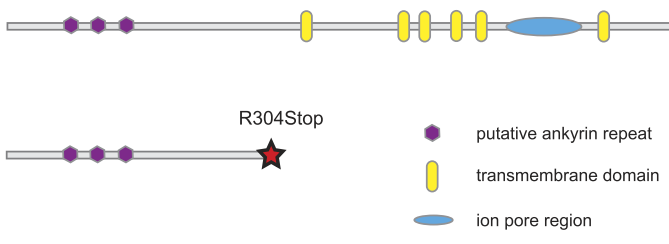

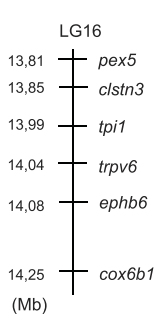

$\mathbf{F}$

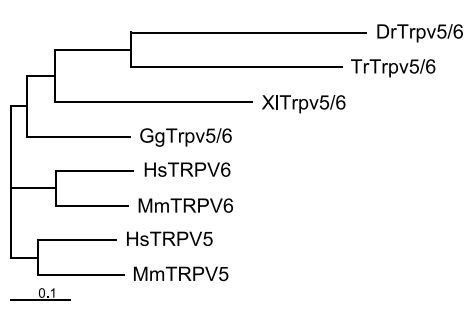

Figure 1. Phenotypic description and mapping of mus. A) Bone (red) and cartilage (blue) staining of sibling and mutant embryos at $7 \mathrm{dpf}$. Top panels: ventral view of sibling, mild mutant, and severe mutant phenotypes, respectively. Bottom left and middle panels: embryos in side view. Bottom right panels: detail of the tip of the notochord. Key skeletal elements are indicated: ps, parasphenoid; op, opercle; th, teeth; oto, otoliths; tn, tip of the notochord; cl, cleithrum; cen, vertebral centrum. Scale bars = $100 \mu \mathrm{m} . B$ ) Overview of meiotic mapping strategy. Numbers indicate number of recombinants/number of mutant embryos and the genomic location (in Mb) according to the Ensemble zebrafish genome browser (Zv9). Markers Rep12 and Rep21 are flanking markers restricting the critical region to $\sim 2 \mathrm{Mb}$. This region was narrowed further by single-embryo mapping using SNP markers. Markers Rep12 and SNPA demarcate a region of interest containing only 1 gene: trpv5/6. C) Sequencing of mutant and heterozygous cDNA. Causative mutation is identified as an A to T substitution resulting in an amino acid change of arginine (R) to a premature stop codon (R304Stop). D) Top: schematic depiction of the wild-type Trpv5/6 protein with putative functional domains indicated. Bottom position of the mutation resulting in a premature stop codon. E) Synteny of chromosome regions at the position of trpv5/6 between zebrafish and human chromosomes. Numbers (Mb) represent the chromosomal positions of the respective genes. The order of a number of genes in the region is conserved between zebrafish LG16 and parts of human chromosome 7 and 12. Note the absence of a second isoform of trpv5/6 in zebrafish. $F$ ) Phylogenetic analysis of TRPV5/6 genes in mammals: Homo sapiens (Hs) and Mus musculus (Mm); birds: Gallus gallus (Gg); amphibians: Xenopus laevis (Xl); and fish: Takifugu rubripes (Tr) and Danio rerio (Dr). Only mammals show 2 distinct TRPV5/6-genes; amphibians and fish genomes only contain 1 trpv5/6 gene. Phylogenetic tree (guide tree) was constructed using the neighbor-joining method in Vector NTI (Invitrogen) and visualized using TreeView software.

SSLP mapping, the region of interest was reduced to $1 \mathrm{Mb}$ using custom repeat markers. Finally, by identification of informative SNPs, the region was further reduced to an interval of $50 \mathrm{~kb}$ containing a single gene: trpv5/6, a member of the TRPV family (Fig.
$1 B)$. Sequencing of the trpv5/6-encoding cDNA in siblings and mutants revealed a single $A$ to $T$ nucleotide change resulting in a premature stop codon at position 304 (R304Stop) of the predicted protein (Fig. 1C). 


\section{Characterization of $\operatorname{trpv5/6}$}

The trpu5/6 gene is composed of 18 exons spanning 31 $\mathrm{kb}$ on LG16. The mutation $m u s^{t 25927}$ is located in exon 9 . The resulting wild-type protein consists of 709 aa with a predicted molecular mass of $81.1 \mathrm{kDa}$ (Fig. 1D). The mutated protein R304Stop results in a severely truncated protein containing only 303 of the predicted 709 aa and is lacking all putative transmembrane domains including the pore region (Fig. $1 D$ ). Mammalian genomes contain 2 genes coding for epithelial calcium channels (ECaCs), which were initially termed ECaC1 (or CaT2; ref. 10) and ECaC2 (CaT1; ref. 6) and later renamed TRPV5 and TRPV6, respectively. The zebrafish, amphibian, and avian genomes contain only one $\mathrm{ECaC}$ isoform (trpv5/6; Fig. $1 E, F)$. Figure $1 E$ shows a large degree of synteny in the region of trpv5/6 on LG16 of the zebrafish genome and chromosomes 12 and 7 of the human genome and illustrates the juxtaposed location of TRPV5 and TRPV6 in the human genome. No second homologue could be detected in zebrafish. Phylogenetic analysis further shows that mammalian TRPV5 and TRPV6 do not cluster together in the same groups, nor do the nonmammlian isoforms. This notion and the adjacent position of TRPV5 and TRPV6 on the same chromosome in mammals support the notion of a gene duplication event in mammals that occurred after the divergence of mammalian and other vertebrate Trpr5/6, which is in line with other phylogenetic studies comparing mammalian isoforms to other vertebrate species (38).

Trpv5/6 mRNA expression was first observed at 24 $\mathrm{hpf}$ in the epithelial layer covering the yolk sac and yolk extension (Fig. 2C). At later stages (4 dpf), expression was still present in the skin, but highest expression levels were in the branchial region where the gills will form (Fig. 2B). In mutant embryos, trpv5/6 expression was absent at $24 \mathrm{hpf}$ (Fig. 2B) and severely reduced at later stages $(4 \mathrm{dpf})$ when compared with siblings (Fig. $2 C)$. Under standard rearing conditions $(0.33 \mathrm{mM}$ total $\mathrm{Ca}^{2+}$ in the E3 embryo medium; ref. 37$), \sim 25 \%$ of the embryos from a heterozygous parental pair showed the phenotype, as predicted for a recessive mutation (Fig. 2A).

\section{Mutants have very low $\mathrm{Ca}^{2+}$ content and can be rescued by extracellular $\mathrm{Ca}^{2+}$}

Since mammalian TRPV5 and TRPV6 are $\mathrm{Ca}^{2+}$-selective channels involved in active $\mathrm{Ca}^{2+}$ reabsorption, we investigated the overall $\mathrm{Ca}^{2+}$ content in mutant $v s$. sibling embryos by atomic absorption spectrometry. Mutant embryos showed a reduction in $\mathrm{Ca}^{2+}$ content of 68\% (8695 vs. $2732 \mathrm{ppb} / \mathrm{mg}$ protein; $P<0.05$ ) when compared with siblings (Fig. 3A). We also measured the phosphorous content of the same samples (Fig. 3B). Here, the difference was much smaller and not statistically significant (18\%; 13,620 vs. $11,204 \mathrm{ppb} / \mathrm{mg}$ protein) but in line with the observed reduction of mineralized bone in the mutant embryos (Fig. 1A). To further test whether the mutants displayed systemic $\mathrm{Ca}^{2+}$ deficiency, we investigated the expression of stanniocalcin 1 ( $s t c 1$ ), an antihypercalcaemic hormone secreted by the corpuscles of Stannius $(39,40)$, fishspecific endocrine organs involved in $\mathrm{Ca}^{2+}$ metabolism (40, 41). Stc1 expression was completely absent in mutant embryos (Fig. 3C) even though the corpuscules of Stannius were correctly formed, as indicated by ron 2 expression. Ron 2 is a tyrosine-receptor kinase expressed in the corpuscules of Stannius and pronephric ducts (Fig. 3D). As the reduced whole-body $\mathrm{Ca}^{2+}$ content was suggestive of a defect in $\mathrm{Ca}^{2+}$ uptake, we exposed mutant embryos to different concentrations of extracellular $\mathrm{Ca}^{2+}$, ranging from a minimal (nominally $10 \mu \mathrm{M}$ total $\left.\mathrm{Ca}^{2+}\right)$ or a standard amount $\left(0.33 \mathrm{mM}\right.$ total $\left.\mathrm{Ca}^{2+}\right)$ to a very high amount (25 mM total $\mathrm{Ca}^{2+}$; Fig. $\left.2 A\right)$. Under conditions of low- $\mathrm{Ca}^{2+}$ availability $(10 \mu \mathrm{M})$, a mortality rate corresponding to the predicted fraction of mutant embryos $(\sim 25 \%)$ was observed. This shows that mutant embryos are hypersensitive to low $\mathrm{Ca}^{2+}$ availability. Under conditions of normal $\mathrm{Ca}^{2+}$ (0.33 $\mathrm{mM}$; the concentration used under standard
A

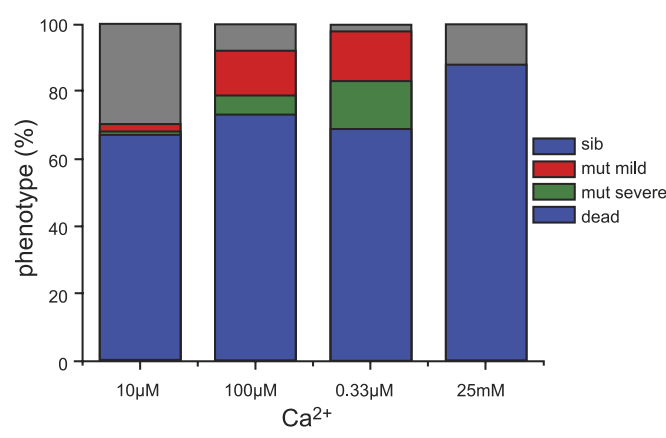

B

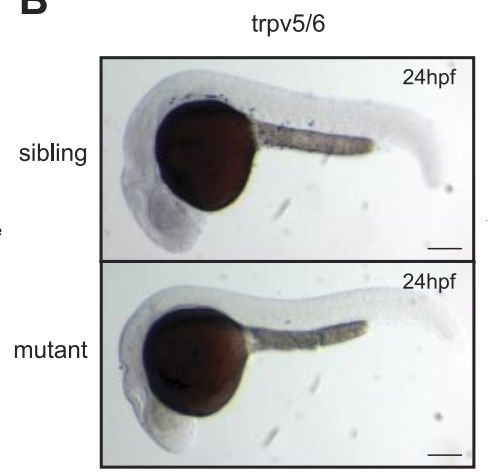

C

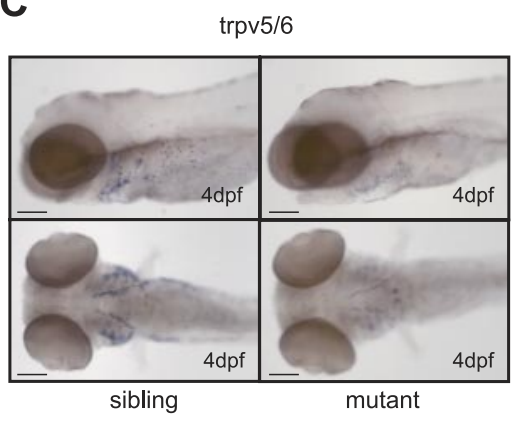

Figure 2. Phenotype dependence on $\mathrm{Ca}^{2+}$ and expression pattern. A) Distribution of the phenotypes in embryos grown in different extracellular $\mathrm{Ca}^{2+}$ concentrations. Same classification of mild and severe phenotypes as in Fig. $1 A$ is used here. In standard growing conditions, the total extracellular $\mathrm{Ca}^{2+}$ concentration is $0.33 \mathrm{mM}$. Stacked bars represent the percentage of phenotypes from a total of 150 embryos/condition from 3 independent experiments. $B, C$ ) trpv5/6 mRNA expression pattern in sibling and mutant embryos using in situ hybridization at $24 \mathrm{hpf}(B)$ and at $4 \mathrm{dpf}(C)$. 
A

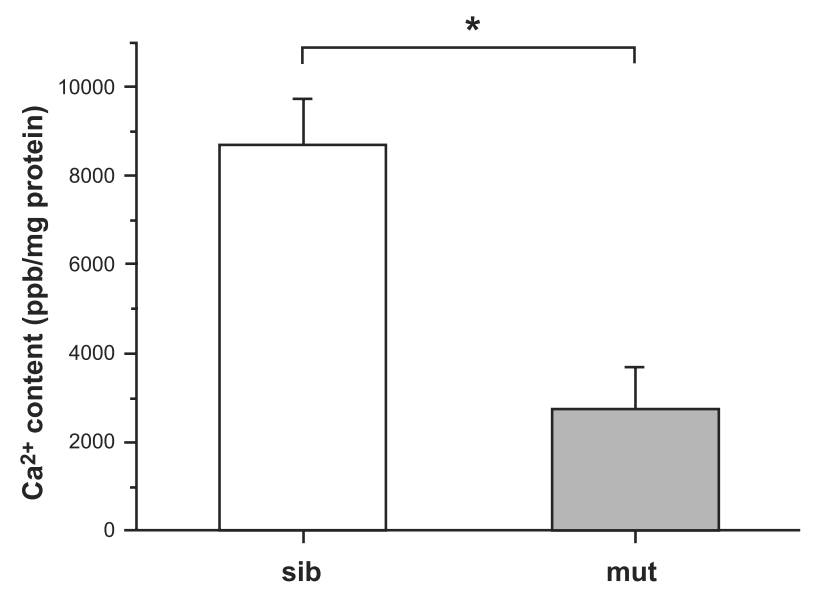

C

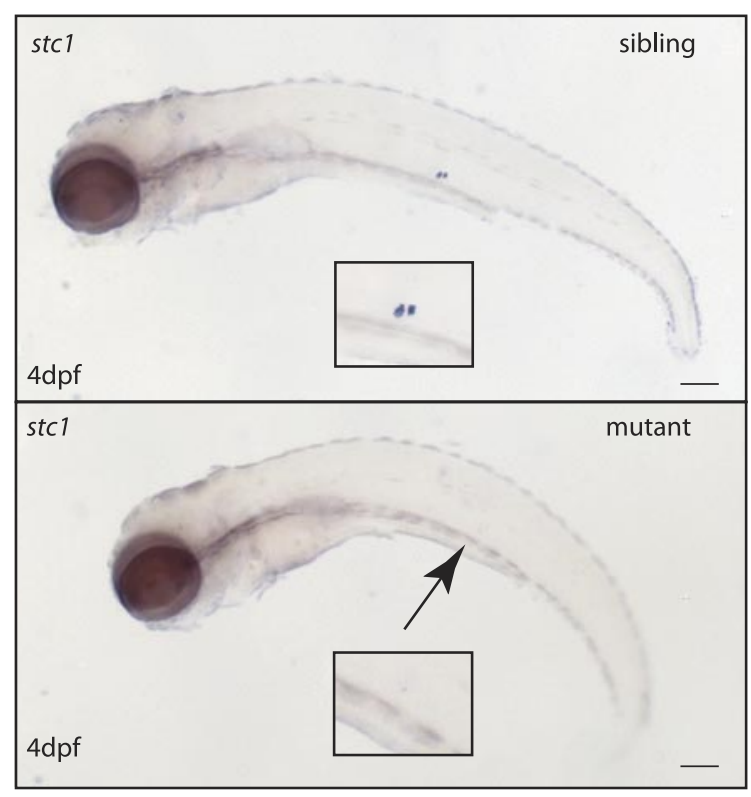

E

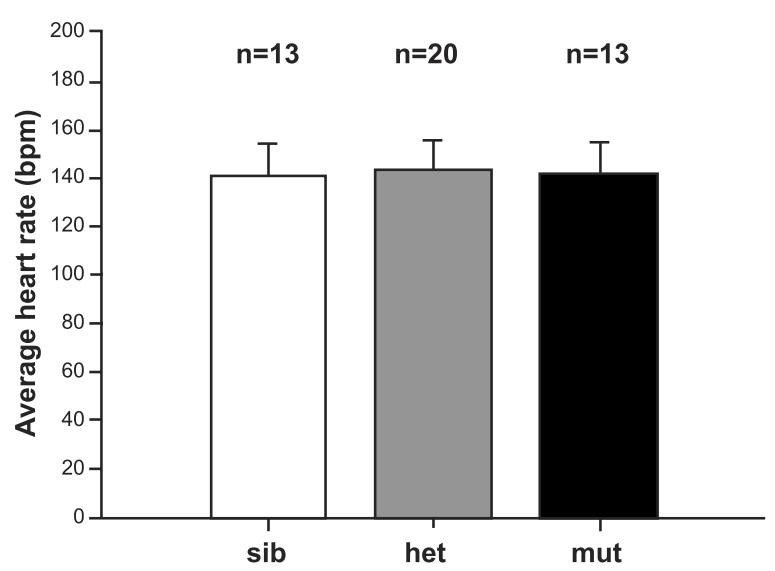

B

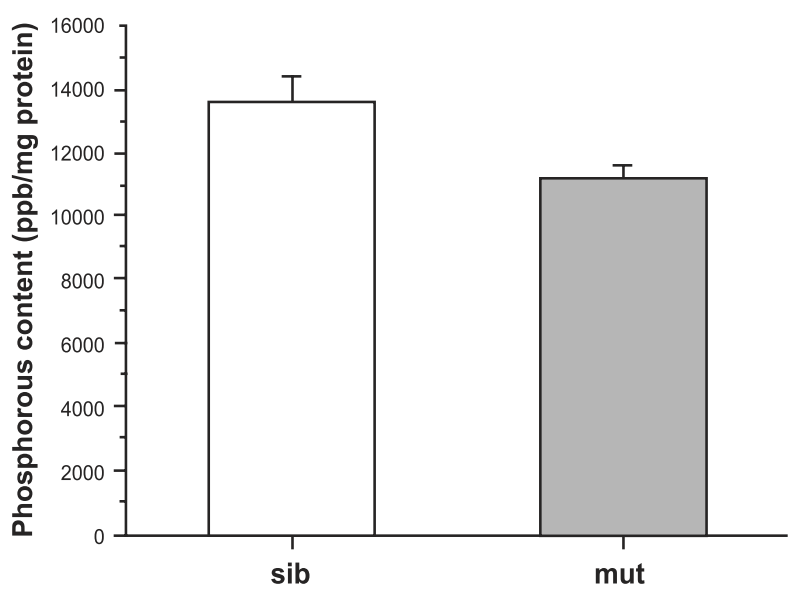

D

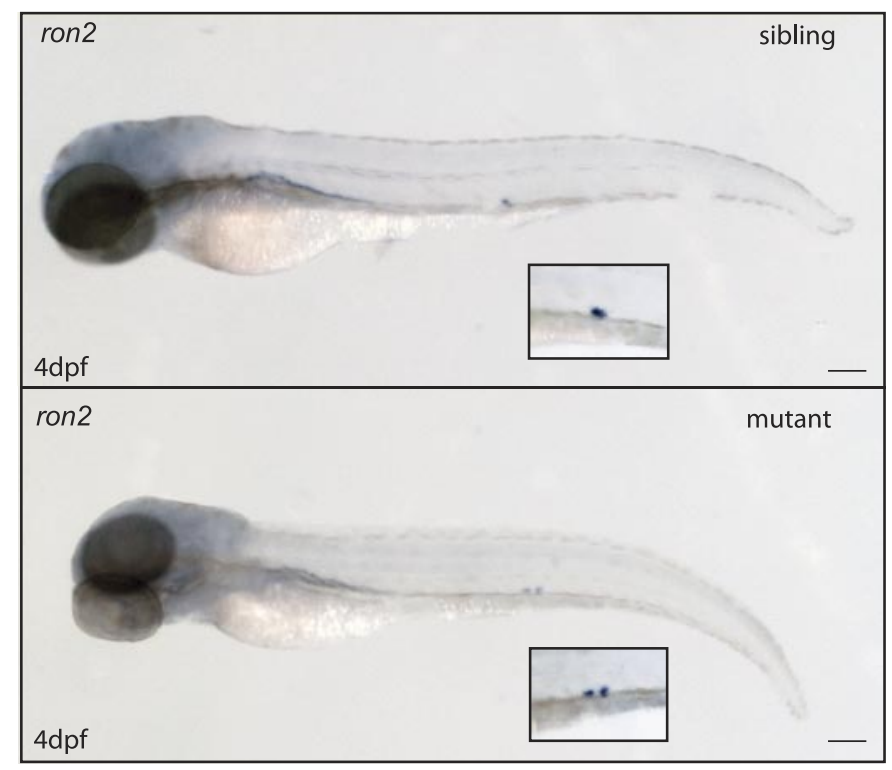

Figure 3. $\mathrm{Ca}^{2+}$ deficiency and disturbed $\mathrm{Ca}^{2+}$ homeostasis in mus mutants. A) Quantification of $\mathrm{Ca}^{2+}$ content in mutant and sibling embryos at $6 \mathrm{dpf}$ using atomic absorption spectrometry. Mutants contain significantly $(P<0.05)$ less $\mathrm{Ca}^{2+}$ when compared with siblings. Measurements are average values of 3 independent experiments measuring a total of 19 single embryos/condition. B) Determination of phosphorous content, as a measure for the amount of phosphate, at $6 \mathrm{dpf}$ in sibling and mutant embryos using atomic absorption spectrometry. Phosphorous content is only modestly lower (not significant) in mutants. This difference is attributed to the presence of less bone in the mutants. Same samples as in $A$ were used. C) Expression of stanniocalcin 1 ( $s t c 1$ ) in embryos at $4 \mathrm{dpf}$ using in situ hybridization. Insets: detailed view of expression in the corpuscules of Stannius. Scale bars $=100 \mu \mathrm{m} . D$ ) Expression of ron 2 in embryos at $4 \mathrm{dpf}$. Expression of ron 2 is present in both siblings and mutants indicating that the corpuscules of Stannius are formed correctly despite lacking stc1 expression. Scale bar $=100 \mu \mathrm{m}$. E) Heart rates in a clutch of mus embryos. Average heart rates were counted in 48 anesthetized embryos at $54 \mathrm{hpf}$. Each embryo was evaluated 3 times before genotyping; $n=$ number of embryos of each genotype that were evaluated. Statistical significance was determined using a Student's $t$ test. Values are depicted as average \pm SD. rearing conditions), the predicted fraction of mutant phenotypes $(\sim 25 \%)$ was observed with an equal distribution between mild and severe phenotypes
(Fig. 2A). At $25 \mathrm{mM} \mathrm{Ca}^{2+}$, no mutant phenotypes were observed (Fig. 2A) but lethality past 7-9 dpf could not be overcome. Taken together, these results 
show that mutant embryos are hypersensitive to low-Ca ${ }^{2+}$ availability and can be rescued by high $\mathrm{Ca}^{2+}$ concentrations in the medium, indicating defects in $\mathrm{Ca}^{2+}$ uptake. We also tested whether other $\mathrm{Ca}^{2+}$ dependent physiological processes are affected in mus mutants. Heart contraction was evaluated, and no difference between genotypes could be observed (Fig. 3E). Mutant embryos also still exhibited a touch response, indicating that skeletal muscles and the sensory system were functional. To address the question of whether the observed bone phenotypes are specifically due to nonfunctional Trpv5/6 channels or an effect secondary to $\mathrm{Ca}^{2+}$ deficiency, we repeated rearing wild-type embryos in different $\mathrm{Ca}^{2+}$ concentrations (Supplemental Fig. S1). When normal embryos were grown in low amounts (5 and 10 $\mu \mathrm{M}$ added $\mathrm{Ca}^{2+}$ ) of extracellular $\mathrm{Ca}^{2+}$, the same bone phenotypes were observed (Supplemental Fig. S1). Stc1 expression in wild-type embryos grown in low $\mathrm{Ca}^{2+}$ was also severely reduced (Supplemental Fig. S1C). Thus, the bone phenotype of mus embryos can be phenocopied in wild-type embryos by severely restricting the extracellular $\mathrm{Ca}^{2+}$ concentration. Taken together, these data support the notion that mus mutant embryos suffer from $\mathrm{Ca}^{2+}$ deficiency, which is primarily reflected by the absence of ossification of the axial skeleton, whereas other functions that highly depend on $\mathrm{Ca}^{2+}$ appear normal at least until $\mathrm{d} 7$. Mineralization is impaired in mus mutants while
differentiated osteoblasts are present

To uncover whether the lack of ossification in mutant embryos was due to general $\mathrm{Ca}^{2+}$ deficiency or to a lack of osteoblast differentiation, we crossed the mus allele into transgenic reporter lines marking early (osx: nuGFP, ref. 34) and mature (osc:GFP) osteoblasts (36) respectively. Osterix expression in mutant embryos was indistinguishable from that in sibling embryos and corresponded to the ossified structures, as visualized by Alizarin red staining (Fig. 4A). Significantly, there was an absence of ossification of the tip of the notochord and the forming vertebrae in mutants, a hallmark of the mutant phenotype. As expected, the number of differentiated (osc-positive) osteoblasts was less than the amount of undifferentiated (osx-positive) osteoblasts, since osteoblast development is still in progress at this stage. Osterix espression indicates that spatially and temporally development of early osteoblasts takes place in mus mutants. Osteocalcin expression, however, was absent in mus mutant embryos (Fig. 4B). To show whether this lack of osteocalcin expression was due to lack of osteoblast differentiation or to dependence of osteocalcin expression on $\mathrm{Ca}^{2+}$ availability, we explored the expression of other late osteoblast markers (colla2, col10a1) using in situ hybridization (Fig. 4C). The expression patterns of both colla2 and col10a1 were indistinguishable between siblings and mutant em-
A

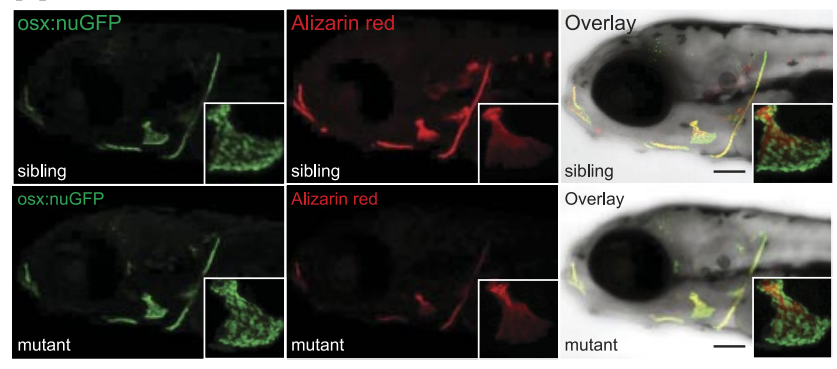

C

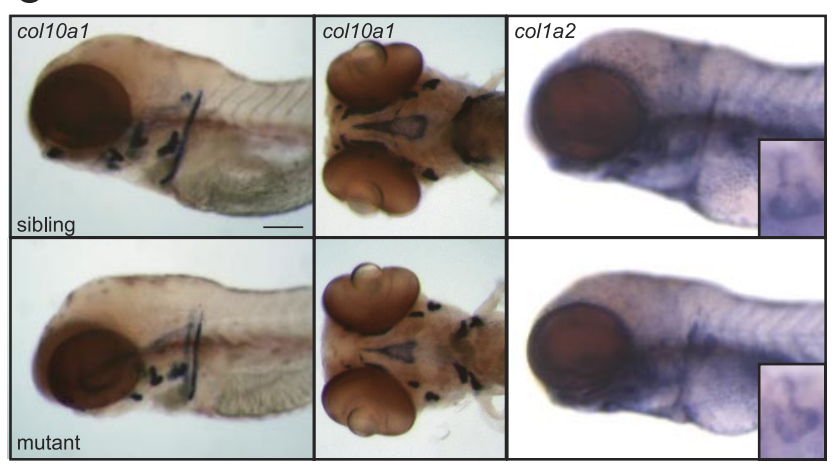

B

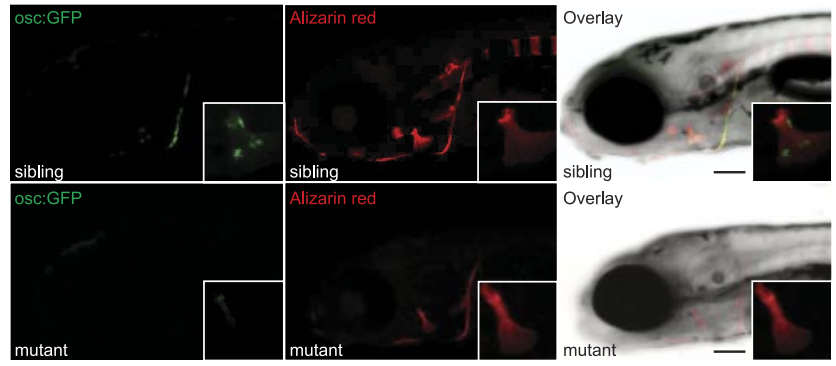

Figure 4. Osteoblast differentiation does occur in mus mutant embryos. Confocal imaging of transgenic osteoblast reporter lines in live zebrafish. $A, B$ ) Side view of sibling (top panels) and mus embryos (bottom panels) at $6 \mathrm{dpf}$. Green channel shows osx:nuGFP expression; red channel marks the ossified matrix stained with Alizarin red. A) Osterix expression in siblings and mus mutants is comparable, indicating the presence of early osteoblasts at sites of ossification in the craniofacial skeleton. Right panel shows an overlay of the fluorescence images with the bright field image. Insets: magnified view of the opercle. B) Osteocalcin is expressed in siblings in the cleithrum and opercle, sites where mineralization is first detected. In mus mutants, no osteocalcin expression is observed. Images are maximal projections from a series of confocal stacks of each embryo. At least 4 embryos/genotype were analyzed in at least 2 separate experiments. C) Expression of additional late osteoblast markers in sibling and mus embryos at 4 dpf. Two markers of differentiated osteoblasts, colla 2 and col10a1, were examined using in situ hybridization. Colla 2 and colloal expression is shown at the cleithrum, opercle, parasphenoid, teeth on the 5th branchial arch, and lower jaw, which are the first elements to be mineralized. Insets: details of the opercle showing colla2 expression. No differences between sibling and mus embryos were detected. Expression patterns of 20-30 embryos of a single clutch were analyzed; embryos used for imaging were subsequently genotyped. Scale bars $=100 \mu \mathrm{m}$. 
bryos; the elements that are first to mineralize showed the presence of differentiated osteoblasts: cleitrum, opercle, teeth on the fifth branchial arch, parasphenoid, and Meckel's cartilage. The expression pattern of an additional late osteoblast marker, sparc (osteonectin), also showed no difference in expression in mutant vs. sibling embryos (Supplemental Fig. S3). Since only the osteocalcin expression pattern was altered in the mutant embryos, we concluded that mature osteoblasts exist in mus mutant embryos and that osteocalcin expression is dependent on the availability of sufficient $\mathrm{Ca}^{2+}$, while expression of other markers is not.

\section{Trpv5/6 is a $\mathrm{Ca}^{2+}$-selective cation channel}

To investigate the characteristics of Trpv5/6, wild-type Trpv5/6 was expressed in HEK293 cells, a well-established overexpression host, and ion currents were recorded in whole-cell patch-clamp experiments. In divalent cation-free conditions with $\mathrm{Na}^{+}$or $\mathrm{K}^{+}(150 \mathrm{mM})$ as the sole extracellular cation, we measured strongly inwardly rectifying currents that reversed around $0 \mathrm{mV}$, whereas no inward current could be measured when the large cation $\mathrm{NMDG}^{+}$was the only extracellular cation (Fig. 5A). These data indicate that Trpv5/6 is an inwardly rectifying cation channel, permeable to $\mathrm{Na}^{+}$ and $\mathrm{K}^{+}$. In isotonic $\mathrm{CaCl}_{2}$ solution $(100 \mathrm{mM})$, the reversal potential shifted toward positive potentials, indicative of a $\mathrm{Ca}^{2+}$-selective current (Fig. $5 B$ ). From the reversal potential of $56 \pm 7 \mathrm{mV}$, we calculated a relative permeability $\left(\mathrm{P}_{\mathrm{Ca}} / \mathrm{P}_{\mathrm{Na}}\right)$ of $120 \pm 13$. We also measured significant permeability for $\mathrm{Ba}^{2+}\left(\mathrm{P}_{\mathrm{Ba}}\right)$ $\mathrm{P}_{\mathrm{Na}}=38 \pm 13$ ), whereas no inward currents could be measured with $\mathrm{Mg}^{2+}$ as the sole charge carrier (Fig. $5 B$ ). Increasing extracellular $\mathrm{Ca}^{2+}$ from $1 \mu \mathrm{M}$ to 100 $\mathrm{mM}$ revealed anomalous mole fraction behavior (Fig. $5 C$ ). This is a hallmark of highly $\mathrm{Ca}^{2+}$-selective channels and reflects inhibition of inward $\mathrm{Na}^{+}$current at low $\mathrm{Ca}^{2+}$ concentrations and $\mathrm{Ca}^{2+}$ permeation at higher concentrations. Taken together, these results demonstrate that Trpv5/6 is a $\mathrm{Ca}^{2+}$-selective channel, analogous to mammalian isoforms. Whereas mammalian TRPV5 and TRPV6 are similar in their biophysical properties, they differ in their sensitivity to block by ruthenium red (RR). We found that the RR sensitivity of Trpv5 $/ 6$ was more comparable with that of mammalian TRPV6, with only partial inhibition at $10 \mu \mathrm{M}$ and an $\mathrm{IC}_{50}$ value of $4 \mu \mathrm{M}$ (Fig. $5 D, E$ ). To directly show whether the channel resulting from the mus mutation was functional, we also expressed the mutant channel and ion currents were measured. Almost no current was observed in the presence of $\mathrm{Na}^{+}$(Supplemental Fig. $\mathrm{S} 2 A$ ) or $\mathrm{Ca}^{2+}$ (Supplemental Fig. S2B) in the mutant channel, whereas the wild-type channel was an inwardly rectifying, $\mathrm{Ca}^{2+}$-selective channel (Supplemental Fig. S2A, B). Quantification of the amount of current at $-100 \mathrm{mV}$ in the presence of $\mathrm{Na}^{+}$or $\mathrm{Ca}^{2+}$ is shown in Supplemental Fig. S2C, D. These results confirm that the mutation is a loss-of-function mutation, as predicted from the position of the mutation early in the coding sequence.

We also performed cytosolic $\mathrm{Ca}^{2+}$ measurements to directly show inward $\mathrm{Ca}^{2+}$ transport from the extracellular space to the cytosol via Trpv5/6 (Fig. 6). A concentration-dependent cytosolic response of $\mathrm{Ca}^{2+}$ on addition of increasing amounts of extracellular $\mathrm{Ca}^{2+}$ was observed (Fig. 6). Note that a large cytosolic response was already observed at concentrations $<0.33 \mathrm{mM} \mathrm{Ca}^{2+}$, corresponding to the concentration used in normal E3 medium. This supports the view that Trpv5/6 is capable of epithelial $\mathrm{Ca}^{2+}$ uptake under physiological growth conditions.

\section{DISCUSSION}

The phenotype was termed matt-und-schlapp, referring to the loss of rigidity in the absence of an ossified vertebral column. The expression pattern of trpv5/6 confirms the results of previous studies showing that expression in zebrafish commences at $24 \mathrm{hpf}$ and becomes restricted to the skin and gill area (4). With the use of RT-PCR, however, expression of trpv5/6 was shown in all tissues tested, with highest levels in gill, intestine, and kidney (4). In addition, these researchers showed that the number of trpv5/6-expressing cells is dependent on the extracellular $\mathrm{Ca}^{2+}$ concentration (4). Gill expression has also been shown for trpv5/6 of other fish species (38). We show that levels of mRNA
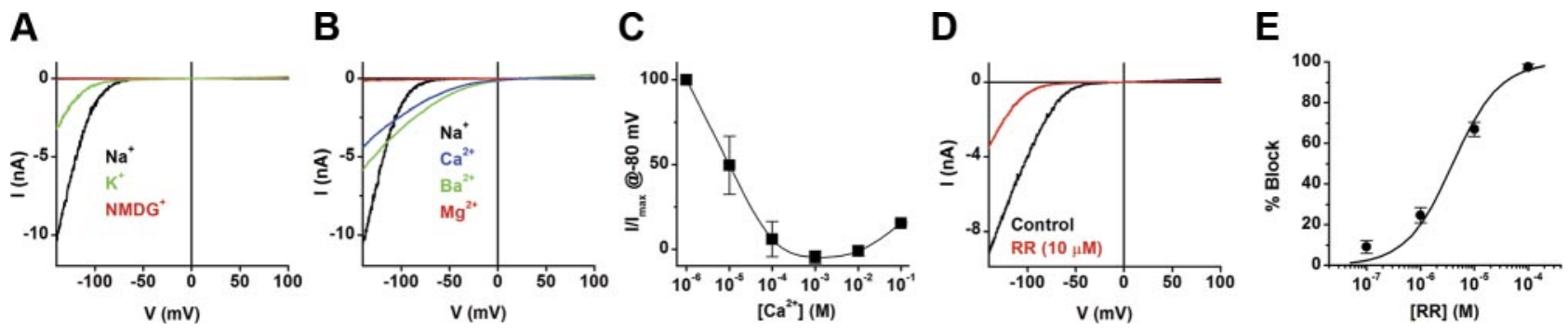

Figure 5. Trpv5/6 is a calcium-selective cation channel. Whole-cell patch-clamp experiments on Trpv5/6-overexpressing HEK293 cells. A) Current-voltage $(I-V)$ relations when using $\mathrm{Na}^{+}$(black trace), $\mathrm{K}^{+}$(green trace), or $\mathrm{NMDG}^{+}$(red trace) as the sole cation in the extracellular solution. B) Comparison of current-voltage relations obtained with $\mathrm{Na}^{+}, \mathrm{Ba}^{2+}, \mathrm{Ca}^{2+}, \mathrm{or}^{2+}$ as the sole extracellular cation. C) Anomalous mole fraction behavior when extracellular $\mathrm{Ca}^{2+}$ is increased from $1 \mu \mathrm{M}$ to 100 mM. D) Current-voltage relations showing partial block of Trpv5/6 currents in the presence of $10 \mu \mathrm{M}$ RR. E) Dose-response curve for the inhibition of Trpv5/ 6 by RR. 
A

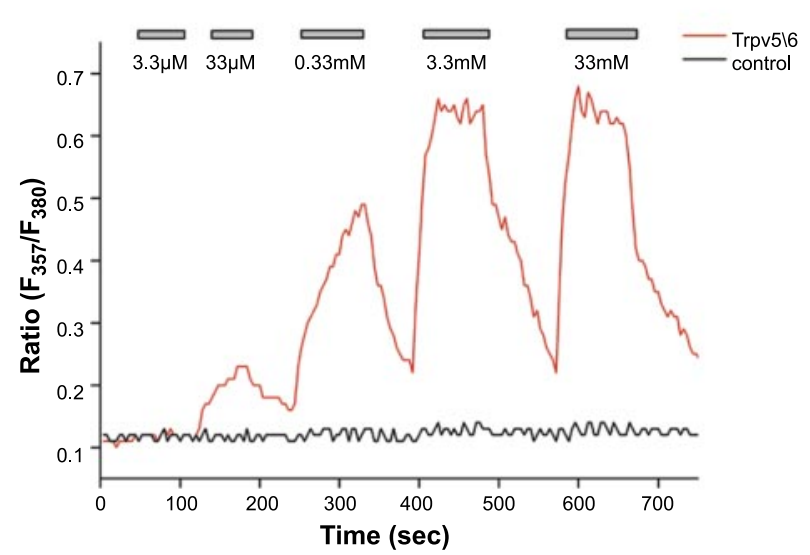

B

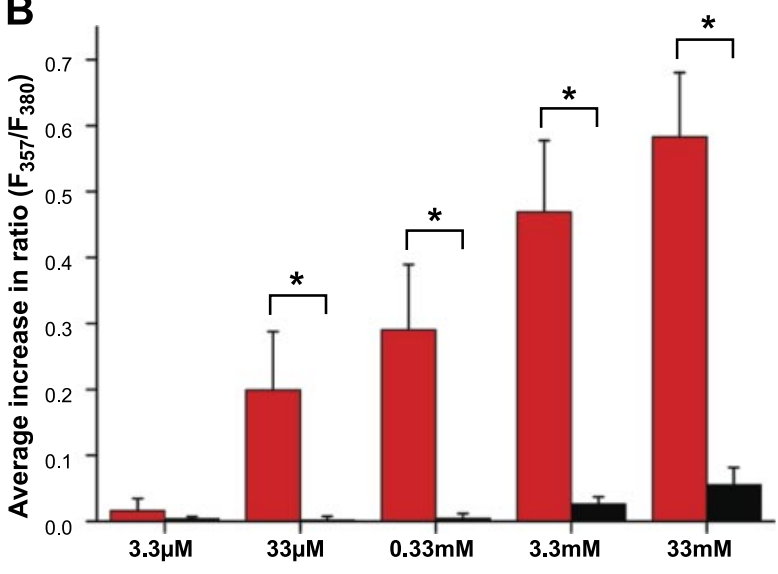

Figure 6. Direct measurement of $\mathrm{Ca}^{2+}$ influx. Cytosolic $\mathrm{Ca}^{2+}$ measurements in HEK293 cells expressing Trpv5/6 (red trace) or with no overexpression (black trace) using Fura-2. A) Representative experiment illustrating responses of cytosolic Ca ${ }^{2+}$ on $^{2}$ addition of increasing concentrations of extracellular $\mathrm{Ca}^{2+} . B$ ) Cytosolic responses of Trpv5/6-expressing cells (red bars) vs. control cells (black bars) were quantified. Bars represent the average cytosolic response of 33 Trpv5/6-expressing cells and 27 control cells from 7 experiments. Values are depicted as average \pm SE. $* P<0.01$; Student's $t$ test.

expression differ between siblings vs. mutants. At 24 hpf, there is no detectable trpv5/6 expression in the mutants, while at $4 \mathrm{dpf}$, there is markedly less trpv5/6 expression in mutant embryos, suggesting degradation of the mutant mRNA by nonsense-mediated decay (42).

The lack of $s t c 1$ expression is not surprising, since $s t c 1$ mRNA levels are regulated by extracellular $\mathrm{Ca}^{2+}$, and, in turn, trpv5/6 expression is down-regulated when $\mathrm{Ca}^{2+}$ is present in sufficient amounts (40). Incubation of embryos in low $\mathrm{Ca}^{2+}$-containing medium resulted in up-regulation of trpv5/6 and down-regulation of stc1 (40), indicative of a tight relation among extracellular $\mathrm{Ca}^{2+}$, stc1, and trpv5/6 expression. Mus mutant embryos experience $\mathrm{Ca}^{2+}$ deficiency since there is no functional trpu5/6, which is (insufficiently) counteracted by downregulation of the antihypercalcaemic hormone stc1.

The fact that the mutant phenotype is observed in the vertebral column is most likely due to developmental timing: vertebrae are formed relatively late in development. During early stages of development, there is sufficient $\mathrm{Ca}^{2+}$ present in the yolk (43), and embryos can take up $\mathrm{Ca}^{2+}$ in adequate amounts for initial growth and survival (44). These sources suffice to allow ossification in those structures that are first to ossify (3 $\mathrm{dpf})$, like cleithrum and opercle. As development proceeds, there is an increasing need for $\mathrm{Ca}^{2+}$ (43) and trpv5/6-independent mechanisms are not able to supply this amount. As a result, no bone is formed in structures that ossify later in development such as the tip of the notochord and the vertebrae.

Our data show that mus mutants suffer from general $\mathrm{Ca}^{2+}$ deficiency. Arguments for this notion are as follows: significantly reduced $\mathrm{Ca}^{2+}$ content, loss of $s t c 1$ expression, phenocopy in wild-type embryos by restricting $\mathrm{Ca}^{2+}$ availability, and hypersensitivity to low $\mathrm{Ca}^{2+}$ and rescue by high $\mathrm{Ca}^{2+}$. This phenotype strongly suggests the existence of a hierarchy in the use of $\mathrm{Ca}^{2+}$ : the limited amount of $\mathrm{Ca}^{2+}$ that is present is used primarily to fulfill other essential cell biological functions such as muscle contraction and secretion at the expense of bone formation.

Skeletal defects have been reported in zebrafish mutants defective in other members of the TRP family. The touchtone/nutria allele (trpm 7 ) shows growth retardation and alterations in skeletal development (45). In contrast, $\operatorname{trpm} 7$ mutations and subsequent disturbance in $\mathrm{Ca}^{2+}$ and $\mathrm{Mg}^{2+}$ homeostasis were found to be associated with elevated levels of $s t c 1$ (46). This is probably due to residual activity, since the allele is not a full loss of function. Furthermore, another TRP channel, TRPV4, has recently attracted significant attention since it was linked to human bone diseases $(47,48)$ and neurological disorders $(49,50)$.

Whereas mammalian TRPV5 and TRPV6 are very similar in their biophysical properties, they differ significantly in their sensitivity to block by $\mathrm{RR}$, with $\mathrm{IC}_{50}$ values of $121 \mathrm{nM}$ for TRPV5 compared with $9 \mu \mathrm{M}$ for TRPV6 (51). We found that the RR sensitivity of zebrafish Trpv5/6 is more comparable to that of mammalian TRPV6, with an $\mathrm{IC}_{50}$ value of $4 \mu \mathrm{M}$. These results, combined with phylogenetic analysis in zebrafish and pufferfish (52) and the absence of a second isoform in fish, suggest that mammalian isoforms have evolved separately from the other vertebrates and the ancestral gene was duplicated after this event. The ancestral isoform probably resembled TRPV6 most and was duplicated as an adaptation to terrestrial life.

The mus phenotype is much more severe than the phenotypes observed for knockouts of its murine counterparts. Trpv $5^{-/-}$mice display reduced renal $\mathrm{Ca}^{2+}$ reabsorption resulting in hypercalciuria and show only mild disturbances in bone structures (26). Trpo5 was also described as essential for osteoclast function (53). Trpv6deficient mice also show impaired $\mathrm{Ca}^{2+}$ homeostasis manifested as decreased intestinal $\mathrm{Ca}^{2+}$ absorption, poor weight gain, decreased bone mineral density, and reduced fertility (25). In addition, TRPV6 is involved in maternal-fetal $\mathrm{Ca}^{2+}$ transport (54). The mildness of phe- 
notypes is best explained by redundancy and compensatory mechanisms: in Trpv5-knockout mice, loss of $\mathrm{Ca}^{2+}$ via the urine is compensated by TRPV6-mediated $\mathrm{Ca}^{2+}$ hyperabsorption in the intestine. On the other hand, Trpv5 up-regulation is not shown to occur in Trpu6-knockout mice, although compensatory hypercalcemic PTH and vitamin-D pathways are activated $(25,55)$. This indicates that TRPV6 is not essential for intestinal $\mathrm{Ca}^{2+}$ uptake, unless $\mathrm{Ca}^{2+}$ availability is restricted $(56,57)$. A double knockout cannot be generated by crossing both strains, since Trpv5 and Trpv6 are located adjacent to each other on the same chromosome. Targeted inactivation of the other known components of transcellular transport, $N c x 1$ and Pmca1, could not reveal their importance in transepithelial $\mathrm{Ca}^{2+}$ transport, since the respective knockout mice are not viable $(58,59)$. Our study shows that if the gatekeeper of the transcellular pathway is deficient, $\mathrm{Ca}^{2+}$ cannot be transported adequately to sustain life. The paracellular pathway or other processes cannot compensate for the loss of this essential component. Zebrafish are an attractive model for these studies since all molecular components are conserved, but they contain only 1 gatekeeper gene and have fewer compensatory mechanisms, resulting in a fully informative loss-of-function phenotype. In this study, we provide for the first time genetic and functional evidence for an essential role of Trpv5/6 in systemic $\mathrm{Ca}^{2+}$ uptake and bone formation. We show that in zebrafish, the transcellular uptake route for $\mathrm{Ca}^{2+}$ in the gills is the most important mechanism for $\mathrm{Ca}^{2+}$ uptake, and Trpv5/6 is a key molecular player in this process. Using electrophysiological techniques and $\mathrm{Ca}^{2+}$ imaging, we could demonstrate that Trpv5/6 is a highly $\mathrm{Ca}^{2+}$-selective channel that allows $\mathrm{Ca}^{2+}$ influx under physiological conditions.

In summary, this study shows for the first time an animal model lacking active transepithelial $\mathrm{Ca}^{2+}$ transport, indicating the essential role of this process to sustain life and enable bone formation. We further show that Trpv5/6 is an essential molecular player in this process. The mus zebrafish mutant line can therefore serve as an important screening tool for regulators of transepithelial $\mathrm{Ca}^{2+}$ uptake, bone density, and related disorders, such as osteoporosis.

The authors thank L. Lieben, G. Carmeliet and B. Nilius for helpful discussions. The authors acknowledge the Hubrecht Imaging Center for expert advice on imaging. The authors thank the Tübingen 2000 screen consortium for identifying the $m u s^{t 25927}$ allele; this mutant was identified while S.S-M was working at Artemis Pharmaceuticals/Exelixis Deutschland. S.S.-M. is supported by the Koninklijke Nederlandse Academie van Wetenschappenand funding from SmartMix. J.V. is a Postdoctoral Fellow of the Fonds voor Wetenschappelijk Onderzoek-Vlaanderen. The authors declare no conflicts of interest. The data reported in this study have been deposited in the GenBank database (accession no. HQ676591; http://www.ncbi.nlm.gov).

\section{REFERENCES}

1. Vangheluwe, P., Sepulveda, M. R., Missiaen, L., Raeymaekers, L., Wuytack, F., and Vanoevelen, J. (2009) Intracellular $\mathrm{Ca}^{2+}$ - and $\mathrm{Mn}^{2+}$-transport ATPases. Chem. Rev. 109, 4733-4759
2. Peacock, M. (2010) Calcium metabolism in health and disease. Clin. J. Am. Soc. Nephrol. 5(Suppl. 1), S23-S30

3. Witten, P. E., and Huysseune, A. (2009) A comparative view on mechanisms and functions of skeletal remodelling in teleost fish, with special emphasis on osteoclasts and their function. Biol. Rev. Camb. Philos. Soc. 84, 315-346

4. Pan, T. C., Liao, B. K., Huang, C. J., Lin, L. Y., and Hwang, P. P. (2005) Epithelial $\mathrm{Ca}^{2+}$ channel expression and $\mathrm{Ca}^{2+}$ uptake in developing zebrafish. Am. J. Physiol. Regul. Integr. Comp. Physiol. 289, R1202-1211

5. Hoenderop, J. G., Nilius, B., and Bindels, R. J. (2005) Calcium absorption across epithelia. Physiol. Rev. 85, 373-422

6. Peng, J. B., Chen, X. Z., Berger, U. V., Vassilev, P. M., Tsukaguchi, H., Brown, E. M., and Hediger, M. A. (1999) Molecular cloning and characterization of a channel-like transporter mediating intestinal calcium absorption. J. Biol. Chem. 274, 22739-22746

7. Lee, G. S., Lee, K. Y., Choi, K. C., Ryu, Y. H., Paik, S. G., Oh, G. T., and Jeung, E. B. (2007) Phenotype of a calbindin-D9k gene knockout is compensated for by the induction of other calcium transporter genes in a mouse model. J. Bone Miner. Res. 22, 1968-1978

8. Hoenderop, J. G., Hartog, A., Stuiver, M., Doucet, A., Willems, P. H., and Bindels, R. J. (2000) Localization of the epithelial $\mathrm{Ca}(2+)$ channel in rabbit kidney and intestine. J. Am. Soc. Nephrol. 11, 1171-1178

9. Kikuchi, K., Kikuchi, T., and Ghishan, F. K. (1988) Characterization of calcium transport by basolateral membrane vesicles of human small intestine. Am. J. Physiol. 255, G482-489

10. Hoenderop, J. G., van der Kemp, A. W., Hartog, A., van de Graaf, S. F., van Os, C. H., Willems, P. H., and Bindels, R. J. (1999) Molecular identification of the apical $\mathrm{Ca}^{2+}$ channel in 1, 25-dihydroxyvitamin D3-responsive epithelia. J. Biol. Chem. 274, 8375-8378

11. Woudenberg-Vrenken, T. E., Bindels, R. J., and Hoenderop, J. G. (2009) The role of transient receptor potential channels in kidney disease. Nat. Rev. Nephrol. 5, 441-449

12. Pansu, D., Duflos, C., Bellaton, C., and Bronner, F. (1993) Solubility and intestinal transit time limit calcium absorption in rats. J. Nutr. 123, 1396-1404

13. Perez, A. V., Picotto, G., Carpentieri, A. R., Rivoira, M. A., Peralta Lopez, M. E., and Tolosa de Talamoni, N. G. (2008) Minireview on regulation of intestinal calcium absorption. Emphasis on molecular mechanisms of transcellular pathway. Digestion 77, 22-34

14. Flik, G., Verbost, P. M., and Wendelaar Bongar, S. E. (1995) Calcium transport process in fishes. In Cellular and Molecular Approaches to Fish Ionic Regulation (Wood, C. M., and Shuttleworth, T. J., eds) pp. 317-342, Academic Press, San Diego, CA, USA

15. Ishihara, A., and Mugiva, Y. (1987) Ultrastructural evidence of calcium uptake by chloride cells in the gills of goldfish, Carassius auratus. J. Exp. Zoology 242, 121-129

16. Liao, B. K., Deng, A. N., Chen, S. C., Chou, M. Y., and Hwang, P. P. (2007) Expression and water calcium dependence of calcium transporter isoforms in zebrafish gill mitochondrionrich cells. BMC Genomics 8, 354

17. Vennekens, R., Owsianik, G., and Nilius, B. (2008) Vanilloid transient receptor potential cation channels: an overview. Curr. Pharm. Des. 14, 18-31

18. Benham, C. D., Davis, J. B., and Randall, A. D. (2002) Vanilloid and TRP channels: a family of lipid-gated cation channels. Neuropharmacology 42, 873-888

19. Nilius, B., Weidema, F., Prenen, J., Hoenderop, J. G., Vennekens, R., Hoefs, S., Droogmans, G., and Bindels, R. J. (2003) The carboxyl terminus of the epithelial $\mathrm{Ca}(2+)$ channel ECaCl is involved in $\mathrm{Ca}(2+)$-dependent inactivation. Pflügers Arch. 445, 584-588

20. Nilius, B., Vennekens, R., Prenen, J., Hoenderop, J. G., Bindels, R. J., and Droogmans, G. (2000) Whole-cell and single channel monovalent cation currents through the novel rabbit epithelial $\mathrm{Ca}^{2+}$ channel ECaC. J. Physiol. 527, 239-248

21. Nilius, B., Vennekens, R., Prenen, J., Hoenderop, J. G., Droogmans, G., and Bindels, R. J. (2001) The single pore residue Asp542 determines $\mathrm{Ca}^{2+}$ permeation and $\mathrm{Mg}^{2+}$ block of the epithelial $\mathrm{Ca}^{2+}$ channel. J. Biol. Chem. 276, 1020-1025

22. Vennekens, R., Hoenderop, J. G., Prenen, J., Stuiver, M., Willems, P. H., Droogmans, G., Nilius, B., and Bindels, R. J. (2000) Permeation and gating properties of the novel epithelial $\mathrm{Ca}(2+)$ channel. J. Biol. Chem. 275, 3963-3969

23. Bronner, F. (2009) Recent developments in intestinal calcium absorption. Nutr. Rev. 67, 109-113 
24. Bronner, F., Slepchenko, B., Wood, R. J., and Pansu, D. (2003) The role of passive transport in calcium absorption. J. Nutr. 133, 1426; author reply 1427

25. Bianco, S. D., Peng, J. B., Takanaga, H., Suzuki, Y., Crescenzi, A., Kos, C. H., Zhuang, L., Freeman, M. R., Gouveia, C. H., Wu, J., Luo, H., Mauro, T., Brown, E. M., and Hediger, M. A. (2007) Marked disturbance of calcium homeostasis in mice with targeted disruption of the Trpv6 calcium channel gene. J. Bone Miner. Res. 22, 274-285

26. Hoenderop, J. G., van Leeuwen, J. P., van der Eerden, B. C., Kersten, F. F., van der Kemp, A. W., Merillat, A. M., Waarsing, J. H., Rossier, B. C., Vallon, V., Hummler, E., and Bindels, R. J. (2003) Renal $\mathrm{Ca}^{2+}$ wasting, hyperabsorption, and reduced bone thickness in mice lacking TRPV5. J. Clin. Invest. 112, 1906-1914

27. Datta, H. K., Ng, W. F., Walker, J. A., Tuck, S. P., and Varanasi, S. S. (2008) The cell biology of bone metabolism. J. Clin. Pathol. 61, 577-587

28. Renn, J., Winkler, C., Schartl, M., Fischer, R., and Goerlich, R. (2006) Zebrafish and medaka as models for bone research including implications regarding space-related issues. Protoplasma 229, 209-214

29. Spoorendonk, K. M., Hammond, C. L., Huitema, L. F. A., Vanoevelen, J., and Schulte-Merker, S. (2010) Zebrafish as a unique model system in bone research: the power of genetics and in vivo imaging. J. Appl. Ichtyology 26, 219-224

30. Walker, M. B., and Kimmel, C. B. (2007) A two-color acid-free cartilage and bone stain for zebrafish larvae. Biotech Histochem. 82 , 23-28

31. Schulte-Merker, S. (2002) Looking at embryos. In Zebrafish: A Practical Approach (Nusslein-Volhard, C., and Dahm, R., eds) pp. 39-58, Oxford University Press, New York

32. Hammond, C. L., and Schulte-Merker, S. (2009) Two populations of endochondral osteoblasts with differential sensitivity to Hedgehog signalling. Development 136, 3991-4000

33. Greenwood, M. P., Flik, G., Wagner, G. F., and Balment, R. J. (2009) The corpuscles of Stannius, calcium-sensing receptor, and stanniocalcin: responses to calcimimetics and physiological challenges. Endocrinology 150, 3002-3010

34. Renn, J., and Winkler, C. (2009) Osterix-mCherry transgenic medaka for in vivo imaging of bone formation. Dev. Dyn. 238, 241-248

35. Kawakami, K., Koga, A., Hori, H., and Shima, A. (1998) Excision of the tol2 transposable element of the medaka fish, Oryzias latipes, in zebrafish, Danio rerio. Gene 225, 17-22

36. Inohaya, K., Takano, Y., and Kudo, A. (2007) The teleost intervertebral region acts as a growth center of the centrum: in vivo visualization of osteoblasts and their progenitors in transgenic fish. Dev. Dyn. 236, 3031-3046

37. Brand, M., Granato, M., and Nusslein-Volhard, C. (2002) Keeping and raising zebrafish. In Zebrafish: A Practical Approach (Nusslein-Volhard, C., and Dahm, R., eds) pp. 7-37, Oxford University Press, New York

38. Shahsavarani, A., McNeill, B., Galvez, F., Wood, C. M., Goss, G. G., Hwang, P. P., and Perry, S. F. (2006) Characterization of a branchial epithelial calcium channel $(\mathrm{ECaC})$ in freshwater rainbow trout (Oncorhynchus mykiss). J. Exp. Biol. 209, 1928-1943

39. Lafeber, F. P., Hanssen, R. G., Choy, Y. M., Flik, G., HerrmannErlee, M. P., Pang, P. K., and Bonga, S. E. (1988) Identification of hypocalcin (teleocalcin) isolated from trout Stannius corpuscles. Gen. Comp. Endocrinol. 69, 19-30

40. Tseng, D. Y., Chou, M. Y., Tseng, Y. C., Hsiao, C. D., Huang, C. J., Kaneko, T., and Hwang, P. P. (2009) Effects of stanniocalcin 1 on calcium uptake in zebrafish (Danio rerio) embryo. Am. J. Physiol. Regul. Integr. Comp. Physiol. 296, R549-R557

41. Pang, P. K., and Pang, R. K. (1974) Environmental calcium and hypocalcin activity in the Stannius corpuscles of the channel catfish, Ictalurus punctatus (Rafinesque). Gen. Comp. Endocrinol. 23, 239-241

42. Peltz, S. W., Brown, A. H., and Jacobson, A. (1993) mRNA destabilization triggered by premature translational termination depends on at least three cis-acting sequence elements and one trans-acting factor. Genes Dev. 7, 1737-1754

43. Chen, Y. Y., Lu, F. I., and Hwang, P. P. (2003) Comparisons of calcium regulation in fish larvae. J. Exp. Zool. A Comp. Exp. Biol. 295, 127-135

44. Chou, M. Y., Yang, C. H., Lu, F. I., Lin, H. C., and Hwang, P. P. (2002) Modulation of calcium balance in tilapia larvae (Oreochromis mossambicus) acclimated to low-calcium environments. J. Comp. Physiol. B 172, 109-114
45. Elizondo, M. R., Arduini, B. L., Paulsen, J., MacDonald, E. L., Sabel, J. L., Henion, P. D., Cornell, R. A., and Parichy, D. M. (2005) Defective skeletogenesis with kidney stone formation in dwarf zebrafish mutant for trpm7. Curr. Biol. 15, 667-671

46. Elizondo, M. R., Budi, E. H., and Parichy, D. M. (2010) Trpm7 regulation of in vivo cation homeostasis and kidney function involves stanniocalcin 1 and fgf23. Endocrinology 151, 5700-5709

47. Krakow, D., Vriens, J., Camacho, N., Luong, P., Deixler, H., Funari, T. L., Bacino, C. A., Irons, M. B., Holm, I. A., Sadler, L., Okenfuss, E. B., Janssens, A., Voets, T., Rimoin, D. L., Lachman, R. S., Nilius, B., and Cohn, D. H. (2009) Mutations in the gene encoding the calcium-permeable ion channel TRPV4 produce spondylometaphyseal dysplasia, Kozlowski type and metatropic dysplasia. Am. J. Hum. Genet. 84, 307-315

48. Rock, M. J., Prenen, J., Funari, V. A., Funari, T. L., Merriman, B., Nelson, S. F., Lachman, R. S., Wilcox, W. R., Reyno, S., Quadrelli, R., Vaglio, A., Owsianik, G., Janssens, A., Voets, T., Ikegawa, S., Nagai, T., Rimoin, D. L., Nilius, B., and Cohn, D. H. (2008) Gain-of-function mutations in TRPV4 cause autosomal dominant brachyolmia. Nat. Genet. 40, 999-1003

49. Deng, H. X., Klein, C. J., Yan, J., Shi, Y., Wu, Y., Fecto, F., Yau, H. J., Yang, Y., Zhai, H., Siddique, N., Hedley-Whyte, E. T., Delong, R., Martina, M., Dyck, P. J., and Siddique, T. (2010) Scapuloperoneal spinal muscular atrophy and CMT2C are allelic disorders caused by alterations in TRPV4. Nat. Genet. 42, 165-169

50. Landoure, G., Zdebik, A. A., Martinez, T. L., Burnett, B. G., Stanescu, H. C., Inada, H., Shi, Y., Taye, A. A., Kong, L., Munns, C. H., Choo, S. S., Phelps, C. B., Paudel, R., Houlden, H., Ludlow, C. L., Caterina, M. J., Gaudet, R., Kleta, R., Fischbeck, K. H., and Sumner, C. J. (2010) Mutations in TRPV4 cause Charcot-Marie-Tooth disease type 2C. Nat. Genet. 42, 170-174

51. Hoenderop, J. G., Vennekens, R., Muller, D., Prenen, J., Droogmans, G., Bindels, R. J., and Nilius, B. (2001) Function and expression of the epithelial $\mathrm{Ca}(2+)$ channel family: comparison of mammalian ECaC1 and 2. J. Physiol. 537, 747-761

52. Qiu, A., and Hogstrand, C. (2004) Functional characterisation and genomic analysis of an epithelial calcium channel (ECaC) from pufferfish, Fugu rubripes. Gene 342, 113-123

53. Van der Eerden, B. C., Hoenderop, J. G., de Vries, T. J., Schoenmaker, T., Buurman, C. J., Uitterlinden, A. G., Pols, H. A., Bindels, R. J., and van Leeuwen, J. P. (2005) The epithelial $\mathrm{Ca}^{2+}$ channel TRPV5 is essential for proper osteoclastic bone resorption. Proc. Natl. Acad. Sci. U. S. A. 102, 17507-17512

54. Suzuki, Y., Kovacs, C. S., Takanaga, H., Peng, J. B., Landowski, C. P., and Hediger, M. A. (2008) Calcium channel TRPV6 is involved in murine maternal-fetal calcium transport. J. Bone Miner. Res. 23, 1249-1256

55. Benn, B. S., Ajibade, D., Porta, A., Dhawan, P., Hediger, M., Peng, J. B., Jiang, Y., Oh, G. T., Jeung, E. B., Lieben, L., Bouillon, R., Carmeliet, G., and Christakos, S. (2008) Active intestinal calcium transport in the absence of transient receptor potential vanilloid type 6 and calbindinD9k. Endocrinology 149, 3196-3205

56. Lieben, L., Benn, B. S., Ajibade, D., Stockmans, I., Moermans, K., Hediger, M. A., Peng, J. B., Christakos, S., Bouillon, R., and Carmeliet, G. (2010) Trpv6 mediates intestinal calcium absorption during calcium restriction and contributes to bone homeostasis. Bone 47, 301-308

57. Kutuzova, G. D., Sundersingh, F., Vaughan, J., Tadi, B. P., Ansay, S. E., Christakos, S., and Deluca, H. F. (2008) TRPV6 is not required for lalpha,25-dihydroxyvitamin D3-induced intestinal calcium absorption in vivo. Proc. Natl. Acad. Sci. U. S. A. 105, 19655-19659

58. Koushik, S. V., Wang, J., Rogers, R., Moskophidis, D., Lambert, N. A., Creazzo, T. L., and Conway, S. J. (2001) Targeted inactivation of the sodium-calcium exchanger (Ncx1) results in the lack of a heartbeat and abnormal myofibrillar organization. FASEB J. 15, 1209-1211

59. Okunade, G. W., Miller, M. L., Pyne, G. J., Sutliff, R. L., O'Connor, K. T., Neumann, J. C., Andringa, A., Miller, D. A., Prasad, V., Doetschman, T., Paul, R. J., and Shull, G. E. (2004) Targeted ablation of plasma membrane $\mathrm{Ca}^{2+}$-ATPase (PMCA) 1 and 4 indicates a major housekeeping function for PMCA1 and a critical role in hyperactivated sperm motility and male fertility for PMCA4. J. Biol. Chem. 279, 33742-33750

Received for publication February 11, 2011. Accepted for publication June 2, 2011. 